\title{
Development of Chinese-Russian Relations Within the SCO
}

\author{
Wu Ting \\ Teather of Northwest Normal University, Lanzhou, China \\ Corresponding author. Email: wutingnina@163.com
}

\begin{abstract}
The SCO was created in 2001, at the moment, as one of the most successful global initiatives, in fact determines the foreign policy vector of development of not only a significant region of the planet, but also the world as a whole. A huge role in the success and effectiveness of the project belongs to Russia and China. This article is devoted to the study of Russian-Chinese relations. The author pays special attention to the role of the Shanghai Cooperation Organization in this process. It does not make sense to call the SCO a "Chinese" or "Russian" project, since the SCO is an original integrative association with an independent, balanced and integrative development vector. Therefore, without a doubt, the role of the SCO in RussianChinese relations can be positioned as the first concrete and successful experience of rapprochement and joint constructive "project" development.

Economic sanctions hinder the development of this process, but the fact of their presence does not indicate the erroneousness of the chosen strategy, but the anxiety of the closest competitors that the project will be successful. The cultural cooperation of the Russian Federation and China has a long long history. However, since 2002, cooperation has intensified. Mutual events are held regularly. They attract wide attention of residents of both states. These "other" forms of manifestation of public and public diplomacy contributed to the establishment of trustful and mutual respectful relations between the peoples of the PRC and the Russian Federation.

The result of the development of this direction was an increase in interest in history, culture, science, lifestyles of the peoples of the Russian Federation and China, the tourist flow increased. Today, the SCO continues to develop dynamically, actively and efficiently adapting to modern world realities.
\end{abstract}

Keywords: Russia, China, cooperation, Shanghai cooperation organization, policy

\section{INTRODUCTION}

The modern world is under active development. Former international agreements have become burdensome for a number of countries. However, overthrowing the old, these countries do not offer a new one, striving for sole domination. In fact, they are pushing humanity back to the "cave" (descriptor) era of international relations.

At present, the theory of a "unipolar world" with the dominance of "the right of the strong" is giving way to the concept of a "multipolar world" and a "community of a unified fate of mankind".

In this regard, the study of the valuable experience of the first models of political integrative polysemantics, of which the Shanghai Cooperation Organization (hereinafter referred to as the SCO) at present, is of particular importance.
The creation in 2001 of the SCO should be considered as one of the most successful global initiatives, which in fact determine the foreign policy vector of the development of a significant region of the planet and the world as a whole. A huge role in the success and effectiveness of the project belongs to Russia and China, which does not exclude, of course, a long way to develop bilateral relations and jointly overcome a number of obstacles and limitations [1].

\section{METHODOLOGY}

The purpose of this article is to study the role and influence of the SCO in Sino - Russian relations.

The research methods are the principles of a systemic and integrated approaches, widely used in modern political science, including methods of comparative, political science and prognostic analysis. One of the essential components of the theoretical basis of the study is the 
principles of historicism and objectivity, as well as the structural-functional approach, which consists in studying events, phenomena and facts not in isolation from each other, but in the aggregate and logical relationship.

The following methods were used in the text of the study:

- The method of a systematic approach. It was used in the analysis of factual and theoretical material;

- Methods of working with historical sources. These methods were used in the analysis of historical sources for the truth of the information contained and the impartiality of its interpretation and use;

- The method of parallel (simultaneous) analysis of sources. This was used in the study of controversial and controversial events that have different interpretations and interpretations in various scientific schools and areas;

- Methods of analysis and synthesis. These methods were used in processing the factual component and building the text of the study.

\section{RESULTS AND DISCUSSIONS}

The historical background (the actual platform) of creating the SCO was as follows. With the collapse of the USSR (1991), there were "not codified", i.e. undefined in the form of a specific document, agreements between the USA and the Russian Federation on the voluntary refusal of the "only superpower of the world" the United States to "not play" in the field of national interests of the Russian Federation. Therefore, the "initial" geopolitical position in the studied region in the 90 s of the 20th century should be considered:

1. The region turned out to be, in fact, "dropped out" of "big geopolitics". This was done deliberately in order to eliminate managerial elites oriented toward the Russian Federation and replace them with part of the national proAmerican elites and part of the young regional clan elites that came to power as a result of wars and color revolutions.

2. The North and North-West of the region were formally recognized by the United States as the "zone of influence of the Russian Federation". In reality, the United States systematically prepared the "ground" for the formation of an anti-Chinese "containment" barrier.

3. Russia "in fact" did not control the specified region and quite often defended not so much its interests as US projects that were promoted as "joint" or objectively necessary for "security of the world as a whole".

4. The PRC was well aware of the importance and prospects of the region and did not recognize the direct and hidden claims to it from the United States. At the same time, the possibilities for China to act in the region were limited by a variety of reasons, including the weakness of the "pro-Chinese" regional elites.

In addition, there was no single point of view in the PRC on the direction and scope of actions in the zone of influence of the Russian Federation at the moment.
5. Relations between the Russian Federation and the PRC have lost their former tension, but the United States actively supported and promoted various political, economic, and cultural "phobias" in relation to the PRC in the countries of the region. In relation to the Russian Federation, through the US-controlled political and economic elites, the media and controlled broadcasting channels, views on China as an unreliable ally, a possible aggressor and potential geopolitical opponent of Russia as an integral part of the "Western" civilization were widely supported [2].

However, the United States and Western European countries have ceased to comply even with these "gentlemanly arrangements" over time. As a result, this same influence in the so-called "western zone" of the influence of the Russian Federation was eliminated, the NATO bases were very close to the borders of Russia.

After that, the United States tried to sharply intensify its activities, aggressively acting in Tajikistan, Kyrgyzstan and Afghanistan in the "eastern zone of interests" of the Russian Federation.

The United States declared Central Asian states a zone of its long-term strategic interests in 1997. The region became the object of a number of American initiatives in 1997-1999 [3].

The logical result of which was the adoption of the "Silk Road Strategy Act" by the US Congress in 1999. Officially, this document was purely "economic goals" and announced US strategic plans for Iran. However, the directions of US actions in the region made it possible to assert the existence of other goals [4].

Since these actions went beyond the bounds of international law, an objective need for retaliatory actions arose for China and the Russian Federation.

The Russian Federation has come up with a number of relevant initiatives. The following Russian initiatives were in the "eastern zone":

1. Russian initiatives affected mainly the countries of the former "Soviet space". In other words, they were local, rather predictable and did not represent a fundamental danger to the "West".

2. In fact, the Russian Federation "mobilized" its "last" resources in the region and could not go beyond its own initiative.

At the same time, these actions made it possible to identify in the region the presence of public and political opinion that did not agree with the actions of the United States. This, in turn, became the "proto-basis" of the creation of the future "Shanghai Five" [5].

3 . The created heterogeneous "union" includes states with varying degrees of American influence (and presence), which the United States was quite happy with because it allowed the possibility of manipulation of integration processes and their actual sabotage. For example, the military base of Karshi-Khanabad (2001-2005) has already been deployed in Uzbekistan; Before the invasion of Afghanistan, the Kyrgyz Magas base was deployed by forces of the United States and its allies in 2001. All this 
greatly strengthened not just the US presence in the region, but provided them with all the opportunities to influence the situation in the region.

However, fascinated by the expansion of its presence, the United States could not objectively assess the main geopolitical event of this period - the active objective rapprochement between China and the Russian Federation. This, of course, should be recognized as theoretically expected, but unpleasant practical result for the "collective West".

Therefore, it should be noted that:

1) The SCO project objectively corresponded to the current situation;

2) It is a reciprocal integrative initiative of the countries of the region;

3) The Russian Federation has formed the basis for the $\mathrm{SCO}$ as friendly countries in the region;

4) The PRC came up with an organizational initiative, and, in many ways, identified a significant part of the vector and directions for the development of the future association.

Therefore, the SCO cannot be called a "Chinese" or "Russian" project, since the SCO is an original integrative association with an independent, balanced and integrative development vector.

Consequently, the role of the SCO in Russian-Chinese relations can be positioned as the first concrete and successful experience of rapprochement and joint constructive "project" development.

In this regard, the growth of critical remarks about the insolvency, formality and artificiality of the SCO and the hidden struggle for leadership in it of the Russian Federation and the PRC is far from accidental. Similar statements are:

Firstly, an indicator, on the contrary, of the successful development of the SCO and a statement of understanding on the part of the "Western" community of the huge potential for the development of a new association;

Secondly, an example of the application of the erroneous and prejudiced, in the analysis of the SCO, "Western mentality" based on the "right of the strong" and imperial thinking.

At the same time, it can be stated that one of the goals of the SCO is the desire to "connect" the two centers of the new multipolar world: China and Russia with a free, actively developing geospace, where destructive parties are "not allowed" to enter [6].

Thus, we can talk about the original "Eurasian response", our own version of "globalization" with its regional identification and understanding of the need for careful and respectful preservation of the diverse cultures of the SCO member countries.

The SCO, as an association, does not set the task of creating a hierarchical system with the dominance of individual countries. This is a special vision of equal, equal cooperation based on centuries-old traditions of respect for the rights and point of view of other states.
The SCO is not an aggressive military alliance; the work of the association is not intended to create danger in relation to third countries. Finally, the SCO is not a demarcation barrier of global and local zones of influence, a division of economic spaces and territories.

Different countries are actively functioning in the SCO: superpowers, regional leaders, countries that possess nuclear weapons and do not possess. They are united by a desire to be heard in an effective pragmatic dialogue, i.e. in fact, something that cannot be in collaboration with countries that prefer the model of a "unipolar world" [7].

However, even with such states, the SCO advocates the organization of an equal dialogue and effective cooperation. For example, the USA and other countries received an invitation to participate in the work of the SCO.

This is objective and justified, since within the framework of the SCO of the country, participants and observer countries are working on a number of major problems of our time. Therefore, the joint interaction of the Russian Federation and the PRC to solve a number of problems is especially important. Moreover, a number of problems of the PRC and the Russian Federation have "common roots".

So, initially (2001), the work within the framework of the SCO was aimed at combating terrorism and extremism [8].

China was extremely interested in containing the separatists in East Turkestan. Such movements were active not only on the western borders of the PRC, but also in China itself, for example, in the Xinjiang-Uyghur Autonomous Region and especially in the Kashgar region (Uyghur separatists, etc.).

The Russian Federation was well aware of the explosive risk of strengthening, in the context of the globalization of the labor market, extremist groups in the Islamic states of Central Asia directly bordering on the Muslim regions of the Russian Federation (Bashkortostan, Tatarstan) and in the republics of the North Caucasus.

The development and strengthening of cooperation under this agenda was significantly strengthened at the SCO summits in Astana (Kazakhstan) and St. Petersburg (RF) in 2002 [9].

The results of this type of cooperation were not slow to affect. So, fifteen leaders of gang organizations and extremist groups were destroyed or arrested by 2006 . Other significant achievements were achieved in this area, for example, special attention was devoted to Afghanistan. The positive experience of this phase of joint activities has shown the importance of further integration. It is only natural that the process of integration into the SCO has received a new impetus since 2007. Members of the association signed The Treaty on Long-Term Good Neighborliness, Friendship and Cooperation. Consequently, the first stage of the SCO integration was completed in 2006-2007.

An important part of the unification processes in the SCO, without a doubt, is large-scale economic cooperation. 
2003, when long-term economic cooperation programs were signed, is crucial for the development of this area [10].

This is not just a mutual investment experience for the Russian Federation and China. This is the beginning of a long way of synchronizing national legislations, all kinds of statements, adaptations, mutual co-integration, finally, overcoming a number of mutual fears and distrust, creating a relationship of reliable and long-term partnership and pragmatic trust [9].

Since 2005, joint energy projects have been activated. The results of efforts and the formation of mutual guarantees in the field of investment and economic cooperation also "were not in vain."

Already in 2009, the Russian Federation and China signed an agreement on cooperation in the field of energy worth one hundred billion dollars. The economic cooperation between the two countries has successfully passed the test of time; they continue to improve and develop successfully.

A psychologically important stage in the development of mutual trust was a fundamentally important agreement on the creation of a mechanism for mutual settlements in rubles and yuan.

At the 2014 summit in Dushanbe, the rapprochement of the Russian Federation and the PRC significantly increased in almost all areas of cooperation. A program of "conjugation" (rapprochement) of three projects of regional integration was put forward: incorporation of the SCO, the Customs Union (Customs Union) and the project "The Silk Road Economic Belt" (China) [11].

Preliminary results of the work done were summed up at the 2015 Ufa Summit of the SCO. Particular attention was paid to the specific results achieved in the rapprochement between China and the Russian Federation.

Consequently, the second stage of the SCO integration was completed in 2014-2015.

Currently, it is also possible to ascertain significant achievements in the main areas of cooperation in the framework of the third stage (2016-2019).

So, according to various analysts, mutual investments have fundamentally increased, trade has increased, its character is diversified, from 17 to $19 \%$ of mutual settlements between the Russian Federation and the People's Republic of China are carried out in national currencies. Thus, "the foundation has been laid" for further development in this direction, which in turn makes the "future" of the Russian Federation and China the largest holders (concentrators) of each other's national currencies [12].

Economic sanctions hinder the development of this process; However, the fact of their presence does not indicate the fallacy of the chosen strategy, but the anxiety of the closest competitors that the project will be successful.

The cultural cooperation of the Russian Federation and China has a long long history. It successfully developed during the "Soviet" history. However, cooperation has been intensified since 2002 .

Mutual events are held regularly. They attract wide attention of residents of both states. These "other" forms of manifestation of public and public diplomacy contributed to the establishment of trustful and mutual respectful relations between the peoples of the PRC and the Russian Federation.

The result of the development of this direction was an increase in interest in history, culture, science, lifestyles of the peoples of the Russian Federation and China, the tourist flow increased.

It should be recognized as a fact that the opportunity to get to know each other better helps to overcome a number of psychological and cultural barriers, negative stereotypes, largely imposed on our peoples by "third countries" during the "unipolar world" [13].

An important part of the interaction between the Russian Federation and China, within the framework of the SCO, is military cooperation. In many ways, it has long outgrown the stage of public demonstration of mutual sympathies (the entry of warships into the ports of both states, the exchange of delegations, the mutual celebration of the most important dates of military history, etc.).

It is of fundamental importance to ascertain the coincidence of relations between the PRC and the Russian Federation and the events of the Second World War, the recognition of the inadmissibility of revision and revision of its results, and respect for those who died in the struggle against fascism and militarism. This is another solid foundation in relations between China and the Russian Federation [14].

Therefore, it is no coincidence that the deepening of military cooperation between the two states. Joint military exercises of the SCO member countries are held in 2003. This experience should also be considered successful. Therefore, since 2005, regular joint training has been held, and the joint exercises of the armed forces of the Russian Federation and China (Peace Mission, etc.) since 2006. Military cooperation of this level, in fact, leads to the strengthening of mutual trust. In this part of the interaction between the Russian Federation and the PRC, experts note the presence of significant potential, especially now, given the sanction pressure of the United States.

Xi Jinping, President of the PRC, taking into account the level of development of Russian-Chinese relations, called them exemplary [15].

It should be noted that the presence of President $\mathrm{Xi}$ Jinping at the St. Petersburg Economic Forum (June 2019) as the Chief Guest was not just a statement of the highest level of economic cooperation in the history of the PRC and the Russian Federation, but also the opportunity to discuss and, consolidate, the opinion of the Russian Federation and the PRC on the whole a number of fundamental issues in the development of the SCO.

Therefore, it is quite natural that V.V. Putin, President of the Russian Federation, and Xi Jinping, President of the PRC, positioned a significant part of the agenda of the 
SCO countries summit held in Bishkek (Kyrgyzstan) on June 13-14, as "united or close".

\section{CONCLUSION}

Thus, the SCO continues to develop dynamically, actively and effectively adapting to modern world realities:

1) Currently, the SCO includes: China, Russia, India, Pakistan, Kazakhstan, Tajikistan, Kyrgyzstan, Uzbekistan. Observer countries are Afghanistan, Belarus, Iran, and Mongolia. Directions of activity, number of participants, their forms of interaction, incorporation panels are constantly changing and improving.

2) The participating countries adopted the SCO Development Strategy until 2025.

3) The Qingdao summit of the SCO in 2018 made it possible to talk about the actual presence of the "Shanghai Spirit", which is extremely important in the current world foreign policy environment [16].

Xi Jinping, President of the PRC, stated that:

1) The SCO is an example of an international association of the "new type". An organization of members that together have a responsibility to ensure security.

2) The concept of global governance in the spirit of joint consultations is being successfully implemented in the $\mathrm{SCO}$, on the basis of the UN Charter.

3) The principle of "mutual benefit and win-win", multilateralism and free trade is developing effectively in an economic partnership.

4) SCO is an example of inclusiveness and mutual learning [17].

V.V. Putin, President of the Russian Federation, in an interview with Xi Jinping, President of the PRC, noted that no matter how successfully relations between the RF and China develop, there is always the opportunity to achieve a greater level of cooperation and integration [18]. Thus, we can state that the SCO:

1) A successful, modern, quickly adaptable mechanism that meets all the latest challenges and is capable of effective answers to them;

2) An open, progressively developing example of the international association of the 21st century, capable of solving the global problems of mankind;

3) An important, integrative component of cooperation in all areas between the Russian Federation and China.

\section{REFERENCES}

[1] Zhong Zanpin, "One belt - one way" as a new form of dialogue between China and civilizations, Yaroslavl Pedagogical Bulletin 1 (2018) 239-243.

[2] Chen Xiaoqin, Analysis of Chinese-Russian energy interests within the SCO, Bulletin of the Institute of international relations 5 (2011) 89-94.
[3] O. Ostroukhov, China's Foreign policy in the years of reforms and prospects for its development, World economy and international relations 3 (1999) 515 .

[4] A. Ulam, Expansion and Coexistence. The History of Soviet Foreign Policy 1917-73, The Viking Press, New York, 1973.

[5] Zhang Wenwei, Shanghai cooperation organization: achievements, opportunities, challenges. Zhongguo weijiao xueyuan, Beijing, 2004.

[6] D.V. Gordienko, Prospects for changing the level of economic security of the SCO member States in the implementation of the silk road Economic belt strategy, in: Asia-Pacific region: problems of global and regional dimensions of security, Moscow, 2018, pp. $195-266$

[7] History of relations between Russia and China. Help, RIA Novosti, Available at: http://www.rian.ru/spravka...html.

[8] History of the Russian-Chinese friendship Society, Russian-Chinese friendship society, Available at: http://orkd.ifes-ras.ru/index.php?page=history.

[9] Liu Zaiqi, China's foreign policy and prospects for Sino-Russian relations, World economy and international relations 9 (2004) 85-96.

[10] Zhang Baijia, Historical review of the evolution of China's foreign policy during the period of reform and expansion of foreign relations (1992-2002), Problems of The Far East 6 (2003) 40-51.

[11] Zhao Tingyang, All-Under-Heaven and Methodological Relationism. An Old Story and New World Peace, in: Contemporary Chinese Political Thought: Debates and Perspectives, Fred Dallmayr, Zhao Tingyang (Eds.), The University Press of Kentucky, 2012.

[12] Sun Yuehuatsu, Political interaction of the Russian Federation and China in the BRICS and SCO, Social and humanitarian knowledge 6 (2018) 276-283.

[13] E.I. Ganshina, Russian - Chinese humanitarian cooperation in the 90 s of the 20th century, Vestnik RUDN. Series: "International relations" 1 (2015) 8897.

[14] M.Sh. Dzhantaleeva, SCO: problems in relations between member States and prospects for further 
development, The Caspian region: politics economy culture 2(55) (2018) 78-83.

[15] Xi Jingping, He delivered a speech at the St. Petersburg International Economic Forum in Russia, Available at: www.russian.cri.cn.

[16] Russian-Chinese trade and economic cooperation, Ministry of economic development of the Russian Federation, Available at: http://www.ved.gov.ru/exportcountries/cn/cn_ru_relati ons/cn_ru_trade/.

[17] Yifan Song, SCO and BRICS: prospects for integration with the participation of China and Russia, Bulletin of the Moscow state regional University. Series: History and political science 2 (2019) 222-228.

[18] V.V. Putin, Vladimir Putin commented on acute international problems at the SPIEF, Available at: www.1tv.ru. 